$1987,36,3$

удК $543.544 .45: 547.424 .1$

У. МЯЭОРГ, Мийа КАРРО, Х. ТИМОТЕУС, Эбба ЛООДМАА

\title{
РАЗДЕЛЕНИЕ ДИАСТЕРЕОМЕРОВ НЕКОТОРЫХ $\beta$-ДИОЛОВ МЕТОДОМ ГАЗОЖИДКОСТНОЙ ХРОМАТОГРАФИИ НА ЖИДКОКРИСТАЛЛИЧЕСКИХ ФАЗАХ
}

\author{
(Представил Ю. Лилле)
}

$\beta$-Диолы широко применяются в качестве экстрагентов борной кислоты из водных растворов [ $\left.{ }^{1}\right]$, пластификаторов $\left.{ }^{2}\right]$, а также в качестве промежуточных продуктов в органическом синтезе [3].

Для решения многих теоретических и практических проблем (стереохимия альдольной конденсации, восстановление дикетонов, кетолов и альдолей) требуется определение диастереомерного состава $\beta$-диолов. Предполагается, что и при экстракции борной кислоты $\beta$-диолами важную роль играет диастереомерный состав экстрагента $\left[{ }^{4}\right]$.

Для разделения диастереомеров обычно используют ГЖХ на капиллярных колонках [5].

В литературе описаны также методики разделения диастереомеров

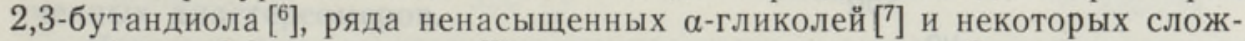
ных эфиров 2,3-бутандиола [ $\left.{ }^{8}\right]$ на насадочных колонках. Однако систематических исследований по разделению диастереоизомеров $\beta$-диолов не проводилось.

Перед нами стояла цель изучить возможности разделения диастереомеров разных $\beta$-диолов на насадочных колонках с жидкокристаллическими фазами и выяснить влияние структуры $\beta$-диолов на этот процесс.

\section{Экспериментальная часть}

ГЖХ проводили на хроматографах «Цвет-152» и «Chrom-5» (ЧССР) с пламенно-ионизационными детекторами, газ-носитель - азот. Были использованы четыре стеклянные колонки:

1) $2,5 \mathrm{~m} \times 2$ мм, $10 \%$ 4-(п-метоксициннамоилокси)-4'-метоксиазобензола (жидкий кристалл Н-158 с мезофазой $167,5-340^{\circ} \mathrm{C}$ ) на Хромосорбе $\mathrm{W}^{\mathrm{T}}$-НP, 100-120 меш;

2) 3 м $\times 3$ мм, 10\% 1,4-бис (4'-н-гептилоксибензоилокси) бензола (жидкий кристалл Н-6 с мезофазой $109,7-199^{\circ} \mathrm{C}$ ) на Хроматоне $\mathrm{N}$-супер, $0,125-0,160$ мм;

3) 2,5 м $\times 3$ мм, 10\% 4,4'-диметоксиазоксибензола (жидкий кристалл c мезофазой $\left.118,2-135,3^{\circ} \mathrm{C}\right)$ на Хроматоне N-AW $-\mathrm{DMCS}, 0,125-$ 0,160 мм;

4) 2,5 м $\times 3$ мм, $5 \%$ Карбовакса $20 \mathrm{M}$ на Хроматоне N-AW-DMCS, $0,125-0,160$ мм.

Изученные нами $\beta$-диолы были синтезированы по опубликованным методикам [9]. Соответствующие физико-химические константы приведены в табл. 1. 
Физико-химические константы изученных $\beta$-диолов

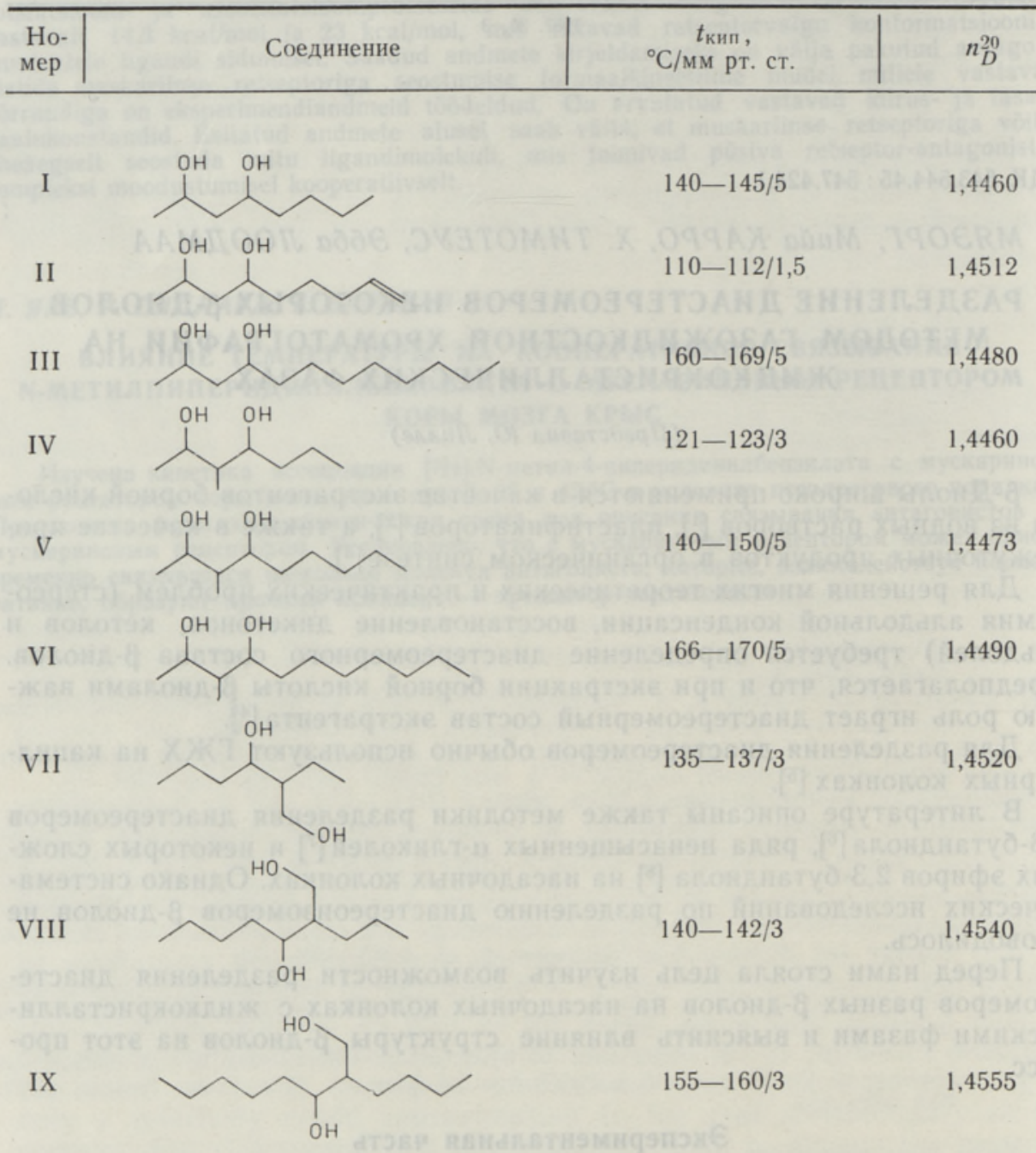

По данным ЯМР-спектроскопии, диастереомеры в этих соединениях содержались в сравнимых соотношениях.

Структура изученных соединений была доказана спектрами ЯМР ${ }^{13} \mathrm{C}$, измеренными на приборе AM-500 фирмы «Bruker» (ФРГ), а также ИК-спектрами (ИКС-29).

Триметилсилильные производные получали, обрабатывая соответствующие диолы триметилхлорсиланом в присутствии пиридина согласно методике $\left[{ }^{10}\right]$. Для ГЖХ анализа использовали $1 \%$-ные растворы $\beta$-диолов в диэтиловом эфире.

\section{Обсуждение результатов}

Условия разделения диастереомеров $\beta$-диолов изучали на жидкокристаллических фазах, которые, по данным литературы, проявляют наивысшую селективность при разделении геометрических изомеров производных алкенов [1'] и замещенных бензолов $\left[{ }^{12}\right]$. В качестве эталона служила полярная изотропная фаза Карбовакс $20 M$ (табл. 2). 
Результаты хроматографического разделения диастереомеров $\beta$-диолов

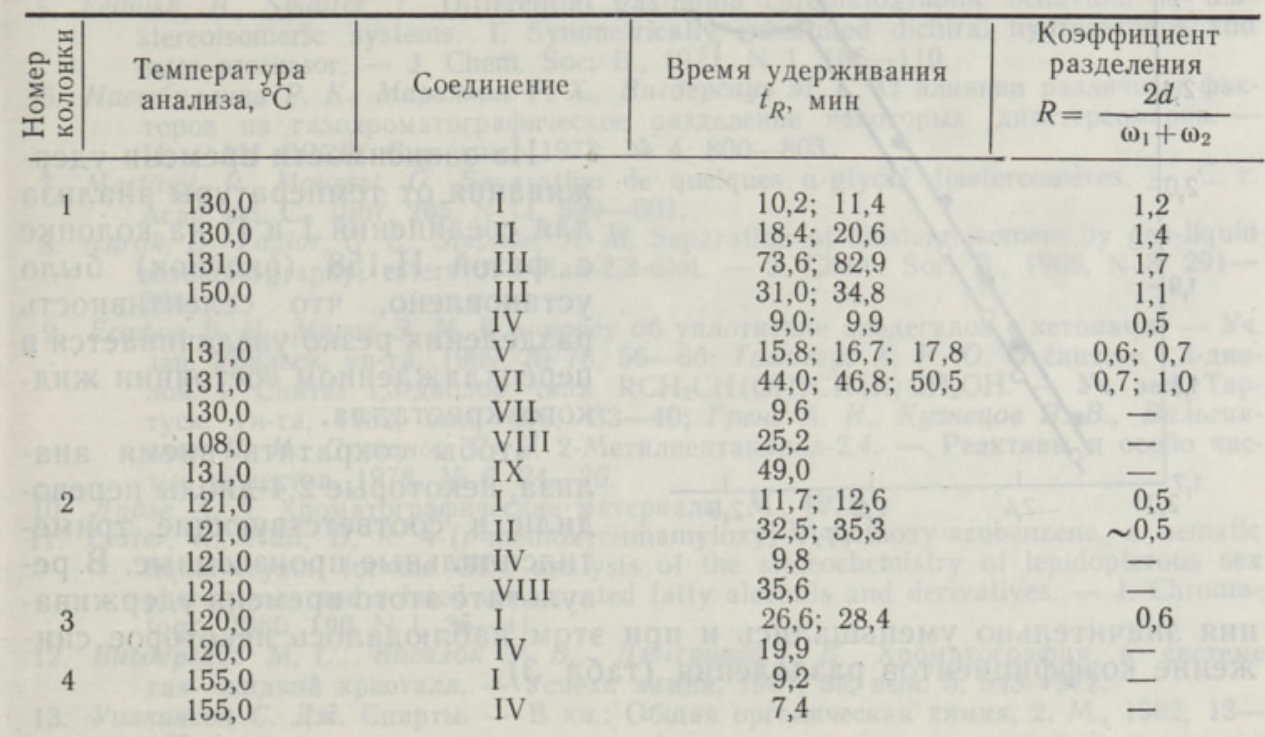

Установили, что наилучшее разделение достигается на 1-й колонке (с фазой Н-158) и посредственное - на 2-й и 3-й колонках. Температура мезофазы 3 -й колонки слишком низка для разделения $\beta$-диолов, a полярная изотропная фаза является неселективной относительно изученных диастереомеров.

Как известно, на жидкокристаллических неподвнжных фазах соединения разделяются согласно разницам соотношений «длина»: «ширина» молекул $\left[{ }^{12}\right]$. Этот принцип наблюдался и в данном случае. С увеличением длины углеводородной цепи коэффициент разделения $(R)$ диастереомеров 2,4-диолов от I до IV значительно увеличивается. При этом последовательность выхода диастереомеров остается неизменной: $t_{R}^{\text {эритро }}>t_{R}^{\text {треo }}$.

Объяснить этот факт можно тем, что строение молекул эритро-изомеров более стержнеобразное, чем трео-изомеров, а следовательно, они легче входят в кристаллическую решетку жидкого кристалла и имеют большее время удерживания.

В случае 3-метилзамещенных 2,4-диолов происходило лишь частичное разделение диастереомеров. ${ }^{*}$ У соединений V и VI два изомера полностью перекрывались, а в случае IV наблюдались только два неразделенных пика.

Диастереомеры с асимметрическими центрами на соседних углеродных атомах (VII-IX) в этих условиях не разделились.

Несомненный вклад в ориентацию изомеров $\beta$-диолов вносит внутримолекулярная водородная связь $\left[{ }^{13}\right]$, которая образуется как в эритро-, так и в трео-изомерах. Но в последнем случае водородная связь вызывает искажение обычной зигзагообразной формы молекулы, что приводит к увеличению соотношения «ширина»: «длина» молекулы и к уменьшению времени удерживания. В пользу этого говорит тот факт, что изомеры 2-алкил-1,3-диолов, у которых водородная связь не имеет такого ориентационного влияния, не разделяются.

* Материалы о конформациях этих соединений и региохимии их получения подготовлены к печати. 


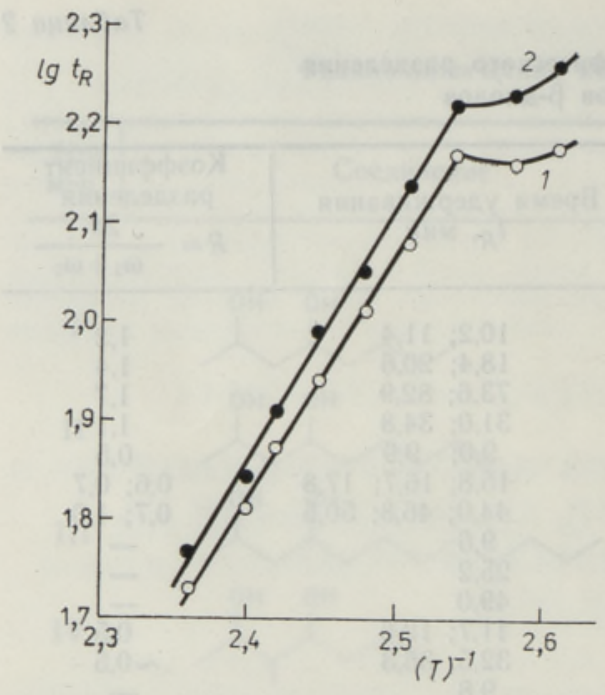

Зависимость времени удерживания трео(1) и эритро-изомеров (2) от температуры анализа на 1-й колонке.

Из зависимости времени удерживания от температуры анализа для соединений I и II на колонке с фазой Н-158 (рисунок) было установлено, что селективность разделения резко увеличивается в переохлажденном состоянии жидкого кристалла.

Чтобы сократить время анализа, некоторые 2,4-диолы переводили в соответствующие триметилсилильные производные. В результате этого времена удерживания значительно уменьшались и при этом наблюдалось некоторое снижение коэффициентов разделения (табл. 3).

Таблица 3

\section{Данные хроматографического разделения триметилсилильных производных некоторых $\beta$-диолов на колонке с фазой Н-158}

\begin{tabular}{c|c|cc}
\hline $\begin{array}{c}\text { Температура } \\
\text { анализа, }{ }^{\circ} \mathrm{C}\end{array}$ & Соедннение & $\begin{array}{c}\text { Время удерживания } \\
t_{R}, \text { мин }\end{array}$ & $\begin{array}{c}\text { Коэффициент } \\
\text { разделення } R\end{array}$ \\
\hline 115 & II & 3,$6 ; 3,9$ & 0,67 \\
130 & III & 8,$8 ; 10,3$ & 1,35 \\
130 & VI & 6,9 & -
\end{tabular}

Полученные данные подтверждают предположение о влиянии разветвленности углеводородной цепи и водородной связи на разделение диастереомеров $\beta$-диолов.

\section{Выводы}

1. Найдена высокоселективная жидкокристаллическая фаза для разделения диастереомеров некоторых $\beta$-диолов на насадочной колонке.

2. С увеличением разветвленности углеводородной цепи $\beta$-диолов разделение диастереомеров ухудшается.

3. Диастереомеры $\beta$-диолов с асимметрическими центрами на соседних углеродных атомах на изученных фазах не разделяются.

4. Предполагается, что внутримолекулярная водородная связь оказывает положительное влияние на разделение диастереомеров 2,4-диолов.

\section{ЛИТЕРАТ У РА}

1. Швари E. М. Экстракционные методы в химии соединений бора. Рига, 1981, 162-163.

2. Rosin, J. USA pat., $2761881,260-635 ; 4.09 .1956$.

3. Redlich, H., Schneider, B., Hoffimann, R. H., Gencke, K.-I. Chirale Bausteine aus Kohlenhydraten. VIII. Synthese der vier isomeren 1,3-Dimethyl-2,9-dioxabicyclo$[3,3,1]$ nonane, - Liebigs Ann. Chem., 1983, N 3, 393-411. 
4. Dale, $J$. The reduction of symimetrical 1,2-and 1,3-diketones with sodium borohydride, and the separation of diastereoisomerie 1,2- and 1,3-diols by means of borate complexes. - J. Chem. Soc., 1961, N 3, 910-922.

5. Feibush, B., Spialter, L. Differential gas-liquid chromatographic behaviour in diastereoisomeric systems. I. Symmetrically subsituted dichiral hydrocarbons and ester precursor. - J. Chem. Soc. B., 1971, N 1, 106-110.

6. Насыбуллина P. K., Марьяхин P. Х., Вигдергауз М. С. О влиянии различных факторов на газохроматографическое разделение некоторых диастереомеров. Изв. АН СССР. Сер. хим., 1973, № 4, 800-803.

7. Martinet, P., Mousset, G. Separation de quelques $\alpha$-glycol diastereomères. - C. r. Acad. sci. C., 1967, 265, N 11, 599-601.

8. Nurok, D., Taylor, G. C., Stephan, A. M. Separation of diastereoisomers by gas-liquid chromatography: esters of butan-2,3-diol. - J. Chem. Soc. B,, 1968, N 3, 291294.

9. Есафов В. И., Марек Э. М. К вопросу об уплотнении альдегидов с кетонами. - Уч. зап. Уральск. ун-та, 1969, № 78, 56-60; Тимотеус Х. Р.-Ю. О синтезе 1,3-диолов. 1. Синтез 1,3-диолов типа $\mathrm{RCH}_{2} \mathrm{CH}(\mathrm{OH}) \mathrm{CH}(\mathrm{R}) \mathrm{CH}_{2} \mathrm{OH}$. - Уч. зап. Тартуск. ун-та, 1982, вып. 616, 33-40; Грень А. И., Кузнецов В. В., Вильгинская И. Н., Степанов Д. Е. 2-Метилпентандиол-2,4. - Реактивы и особо чистые вещества, 1978, № 6, 24-26.

10. Лурье A. A. Хроматографические материалы. М., 1978.

11. Lester, R., Hall, D. R. 4-(p-methoxycinnamyloxy)-4'-methoxy-azobenzene, a nematic liquid crystal for the GLC analysis of the stereochemistry of lepidopterous sex pheromones and related unsaturated fatty alcohols and derivatives. - J. Chromatogr., 1980, 190, N 1, 35-41.

12. Вигдергауз М. С., Вигалок Р. В., Дмитриева Г. В. Хроматография в системе газ-жидкий кристалл. - Успехи химин, 1981, 50, вып. 5, 943-972.

13. Уилкинсон С. Дж. Спирты. - В кн.: Общая органическая химия, 2. М., 1982, 13 158.

Тартуский государственный университет

Поступила в редакцию 8/XII 1986

U. MAEEORG, Miia KARRO, H. TIMOTHEUS, Ebba LOODMAA

\section{MONEDE $\beta$-DIOOLIDE DIASTEREOMEERIDE GAASIKROMATOGRAAFILINE} LAHUTAMINE VEDELKRISTALSETEL FAASIDEL

On uuritud mõnede $\beta$-dioolide diastereoisomeeride gaasikromatograafilist lahutamist vedelkristalseid vedelfaase sisaldavates täidiskolonnides. On leitud kõrge selektiivsusega vedelkristalne faas $\mathrm{H}-158$ ja määratud selle lahutusomaduste sõltuvus temperatuurist. On näidatud $\beta$-dioolide struktuuri mõju diastereomeeride lahutumisele.

\section{U. MÄEORG, Miia KARRO, H. TIMOTHEUS, Ebba LOODMAA}

\section{SEPARATION OF DIASTEREOMERS OF SOME $\beta$-DIOLS BY GAS-LIQUID CHROMATOGRAPHY USING LIQUID-CRYSTAL PHASES}

The GLC separation of some $\beta$-diols stereoisomers using liquid crystal phases have been studied. A highly selective liquid crystal phase H-158 was found and its selectivitytemperature relationship established. The influence of the structure of $\beta$-diols on the separation of diastereomers has been shown. 